\title{
Ortega y la razón histórica en la historia de la filosofía
}

\section{Historical Reason in the History of Philosophy}

\author{
Jesús RUIZ FERNÁNDEZ \\ IES Lázaro Cárdenas de Collado Villalba (Madrid) \\ jjesusruizz@hotmail.com
}

Recibido: 22-02-2010

Aceptado: 29-11-2010

\section{Resumen}

El presente artículo pretende ser un estudio del carácter circunstancial e histórico de la filosofía según Ortega y Gasset, mediante una sistematización de los múltiples datos dispersos en su obra. Muchas vueltas ha dado la bibliografía al término razón vital, y, sin embargo, puede observarse con decepción cómo en las explicaciones del mismo casi nunca aparece lo más importante. Pues lo que Ortega quería decir, por encima de todo, con él, es que no hay filosofía definitiva, ni siquiera la suya. Por eso, la razón, la filosofía está viva. Lo cual no significa que se halle detenida siempre en el mismo punto: hay progreso, la ganancia es en complejidad.

Palabras clave: Circunstancia, historia de la filosofía, Ortega y Gasset, razón histórica.

\begin{abstract}
The current article aims to study the circumstantial e historical character of Ortega y Gasset's Philosophy, organising the multiple dispersed data in his works. Philosophical literature has thought over the term vital reason a lot. However, it can be disappointingly observed that the most important issue hardly appears in its
\end{abstract}


explanations. With it, Ortega meant, above all, that even in his there is no definitive philosophy. Consequently, the reason, the philosophy is alive, which does not mean that we are always the same, since Philosophy is more and more experienced: there is progress, complexity increases.

Keywords: circumstance, history of philosophy, Ortega y Gasset, historical reason.

\section{Introducción}

Me propongo en el presente artículo estudiar uno de los caracteres que, según Ortega y Gasset, la filosofía posee como ciencia o razón: el carácter histórico. Es cierto que a veces el filósofo español se expresa como si la filosofía no fuera una ciencia, cosa que suele ocurrir normalmente cuando la contrapone a la física (cfr. VII: 300; XII: 99; VIII: 37; XII: 159; VIII: 82; IX: 710), ciencia que en sus condiciones actuales, al término de su proceso evolutivo, se ha convertido en mero artificio probable y simbolismo útil, algo que, a juicio de Ortega, no podía considerarse ya conocimiento (cfr. 1994: 57-58; VIII: 282). Sin embargo, es bastante claro que, en general, para Ortega la filosofía es ciencia. Expresiones bastante tardías lo corroboran: «la filosofía es homogénea a las ciencias en cuanto es como ellas conocimiento» (XII: 133), en 1932; o, en 1944, donde aparece como la teoría en sentido máximo (cfr. XII: 320). En este punto Ortega siguió a Husserl, cuya obra, como reza el título de uno de sus ensayos, La filosofía como ciencia estricta, le ubicaba en la ilustre tradición de Platón y Descartes, restauradora de la filosofía como ciencia (cfr. 1949: 372; 1962: 5; 1986: 3 y ss.).

La filosofía posee una serie de caracteres propios que la distinguen de las demás ciencias. Es decir, que no es una ciencia sin más: es, además, filosofía. Pero, en cuanto razón, ciencia o conocimiento -términos sinónimos en Ortega- participa de sus características. Y van a ser precisamente éstas las que vivifiquen la idea tradicional de filosofía que Ortega conservaba; superándola, actualizándola, integrándola en la nueva idea de la vida, que la 'crisis de fin de siglo' había puesto en primer plano. Ortega, en efecto, introduce una importante reforma y actualización en la idea de ciencia, que afectará tanto a su objeto como a su método, y que revertirá en la idea de filosofía.

El objeto de la ciencia siempre había sido el ser, esto es, una unidad inmutable y eterna tras el hecho plural, cambiante y perecedero. Pero ahora éste había de tornarse de parmenídeo en heraclíteo: perspectivista, circunstancial e histórico. Ortega lleva a cabo una reforma de la idea de ser, tornándolo en relativo, plural y cambiante, para poder salvar así el conocimiento absoluto, uno e inmutable. La varita 
mágica con que lo logra es el perspectivismo. Y a este «ser vital» corresponderá un método de conocimiento vital: la 'razón vital'. Razón vital quiere decir que la razón está viva. Hay en ella un elemento dinamizador: la 'dialéctica', uno de los tres elementos fenomenológicos a que se reduce en esencia la razón vital, junto a la epojé y la intuición.

La razón histórica consiste en la aplicación de la razón vital al estudio de la historia, descubriendo en ella la misma razón vital. ${ }^{1} \mathrm{Y}$ aquí es donde entra el tema de la historia de la filosofía. La historia de la filosofía es una ciencia histórica; y, sobre ella, nos proporcionó Ortega una serie de importantes apuntes, sobre todo, la idea de que la menesterosa filosofía se halla sometida a la gleba espacio-temporal, esto es, que la filosofía es circunstancial e histórica. Pero téngase en cuenta que la filosofía no es circunstancial e histórica por ser filosofía, sino por ser ciencia.

\section{Filosofía y circunstancia}

«De la labor hasta ahora llamada historia de la filosofía fuera obligado decir que ni es historia ni lo es de la filosofía, de modo que no puede acaecerle desastre mayor» (VI: 389). En vista de estas palabras, no puede decirse precisamente que Ortega tuviera una buena opinión de la historia de la filosofía de su tiempo. ¿Por qué? Porque no tenía en cuenta al hombre de carne y hueso, esto es, las circunstancias del filósofo. Las doctrinas se exponían como si las hubiese enunciado «el filósofo desconocido»; cuando, por ejemplo, se exponía la filosofía de Kant, lo único de Kant que aparecía era el nombre. Se trataba de una historia espectral de la filosofía, una sucesión de doctrinas que emanaban mágicamente unas de otras. ${ }^{2}$ Frente a esta historia «cinemática», Ortega postuló una historia «dinámica», donde se diera fe de las fuerzas, de las energías humanas que animaban las doctrinas (cfr. IV: 50). Pues no hay historia de la filosofía, sino historia de unos hombres que filosofan (cfr. VIII: 501); y una idea de ayer no influye, propiamente hablando, en otra de hoy, sino que influye en un hombre que reacciona a esa influencia con tal idea» (VI: 393). Un hombre, además, que todo lo que hace, lo hace en vista de las circunstancias (cfr. VI: 348). «Lo que pensamos, y mucho más lo que escribimos, es el ademán con que lo más íntimo de nuestra persona responde a lo circunstante, a lo que es para nosotros la vida en este lugar y día» (II: 170).

\footnotetext{
${ }^{1}$ La razón vital y la razón histórica las estudio en «El método de la ciencia la razón vital», Revista de Estudios Orteguianos, 18, Madrid, 2009, 171-189.

2 Compárense estas líneas con estas otras de Del sentimiento trágico de la vida: «En las más de las historias de la filosofía que conozco se nos presenta a los sistemas como originándose los unos de los otros, y sus autores, los filósofos, apenas aparecen sino como meros pretextos. La íntima biografía de los filósofos, de los hombres que filosofaron, ocupa un lugar secundario. Y es ella, sin embargo, esa íntima biografía la que más cosas nos explica» (1982: 35).
} 
Devolvamos a nuestros pensamientos el fondo en que nacieron [...] Así lo hicieron los hombres mejores: no se olvida Descartes de contarnos que su nuevo método reformador de la ciencia universal le ocurrió una tarde en el cuarto-estufa de una casa germánica, y Platón, al descubrirnos en el Fedro la ciencia del amor, que es la ciencia de la ciencia, cuida de presentarnos a Sócrates y su amigo dialogando en una siesta canicular, al margen del Ilisos, bajo el frescor de un alto plátano sublime, en tanto que sobre sus cabezas las cigarras helénicas vertían su rumor (II:150).

En el "Prólogo a la Historia de la Filosofia", de Bréhier es donde Ortega desarrolla de manera más completa esta nueva forma de historiar. Pero en En torno a Galileo ya la había puesto en práctica, porque, como escribe José Luis Abellán, «cuando Ortega dicta su curso En torno a Galileo, la preocupación que le embarga es la de poner en práctica un nuevo modo de historiar que consiste en desvelar el sustrato vital, anímico y cultural que anida en el hombre renacentista, es decir, el hombre que ha abandonado ya la fe medieval en su plenitud y que está en trance de convertirse en "hombre moderno", cuya fe es ante todo la ciencia» (Ortega, 1996b: 28).

\subsection{Texto y contexto}

La filosofía no es sólo lo expreso en los textos escritos. Los textos tienen detrás todo un contexto implícito, cuyo conocimiento es indispensable para poder entenderlos. «Leer en serio, auténtico leer, es referir las palabras patentes a ese todo latente dentro del cual quedan precisadas y con ello entendidas» (IX: 752: v.t. VIII: 258-259). El texto sólo es posible descollando sobre un contexto, lo mismo que el lenguaje sólo es posible destacando sobre el silencio. Podemos hablar gracias a que callamos la mayoría de las cosas, ya que todo sería imposible decirlo; si pretendiéramos decirlo todo, en realidad no diríamos nada. Ortega distinguió dentro del mundo inexpresado del contexto tres factores: el suelo, el subsuelo y el adversario. El suelo es advertido por el filósofo, pero no lo expresa por resultar obvio; él sabe que el lector lo tiene presente, de modo que no pierde el tiempo en explicitarlo. El subsuelo, en cambio, cae dentro del ámbito de lo que Ortega llamó el contar con, esto es, lo inadvertido de puro cercano, lo que, siendo común a todos los hombres de una misma época, nadie repara en ello, porque es la condición de todo posible «reparar» y el lugar desde donde es posible todo «darse cuenta». El adversario es necesario por la condición dialéctica del conocimiento, porque, en contraste con él, se perfila el pensamiento del filósofo; se trata siempre de un contemporáneo, con el que se coincide en el suelo y en el subsuelo; el filósofo tiene, por tanto, mucho en común con él, y, en efecto, con alguien totalmente ajeno a nosotros, no combatimos (cfr. IX: 394-395, 410; VI: 390; VII: 300-301; V: 233-234; VIII: 392-394).

Desde muy pronto supo Ortega que nuestro cerebro se organiza en la lucha con los idearios ajenos y que la historia de las ciencias es íntegramente la relación de las 
polémicas entre grandes pensadores. Así, las obras clásicas de la filosofía solo tienen una interpretación plausible cuando se las coloca en la perspectiva polémica en que fueron escritas. Por ejemplo, la Crítica de la razón pura, que fue resultado de la polémica de Kant con Leibniz y Hume. «Donde quiera que la germinación de ideas fue activa y enérgica, vivióse en perpetua polémica», a veces dándose en caso extremo dentro de un mismo espíritu, como en Renan, quien «gustaba dejar que disputaran entre sí los lóbulos de su cerebro» (X: 39).

La hermenéutica crítica ha querido ver en Unamuno a este adversario de que estamos tratando (cfr. Cerezo, 1984: Capítulo 2; Lasaga, 2003: 41-42). No es este lugar para tratar ni siquiera mínimamente el importantísimo problema -por lo menos para la filosofía española- de las relaciones Ortega-Unamuno, que requeriría un artículo dedicado expresamente a este fin. Mi posición, desde luego, es que Unamuno es una influencia positiva más que negativa en Ortega. La cita de la nota a pie de página de más arriba está puesta a propósito como ilustración. ${ }^{3} \mathrm{El}$ adversario de Ortega es la Edad Moderna, la razón pura, el idealismo; toda su obra -por lo menos en la 'segunda navegación'- se configura en primer término como un afán de superarlo, de reformar la idea moderna de filosofía para sacar a Europa de la crisis de fin de siglo.

A estas razones obedecen las reticencias que Ortega tenía hacia la escritura. Son innumerables las veces en que se apoya en Platón al exponer su pensamiento, y en este punto le venía bien a la mano. Una de las razones que el filósofo griego esgrimía consistía, como en Ortega, en los límites del lenguaje de cara a la comunicación. Por eso el madrileño tiene presente al ateniense en un artículo en que compara el libro con la revista y el periódico. En efecto, todos estos medios de expresión tienen sus ventajas y, también, sus inconvenientes, pero la desventaja del libro reside en su carácter abstracto (cfr. III: 446-449). «Cenizas de pensamiento» (V: 234) llega a llamar Ortega a los libros. «La casta de los filósofos es la primera realidad de la filosofía. En cierto modo, la filosofía fuera y aparte de los hombres filósofos, es una abstracción y, además, un fragmento. ¿Por qué? Porque toda filosofía es tan compleja que no ha podido jamás ser por entero formulada. No se la puede "decir". Sólo cabe insinuarla mediante algunos gestos que nos pongan en la pista y nos permitan crear por nuestra cuenta, su infinitesimal curvatura». Goethe pensaba lo mismo que Platón:

"la palabra escrita es un subrogado de la palabra hablada". En rigor la conversación es el hombre entero. Platón explicaba a sus discípulos de manera más clara que en sus

\footnotetext{
3 El artículo de Ciriaco Morón Arroyo, «Unamuno y Ortega y Gasset: las variedades de la razón», me parece definitivo de cara al establecimiento de los parecidos y disonancias entre los dos filósofos españoles más importantes.
} 
escritos. De aquí que «el afán de comunicar una filosofía lleve inevitablemente a un deseo de convivencia. Una fuerte filosofía crea siempre un grupo social que ha sido ordinariamente una escuela. En su circuito se opera esa transfusión de sangre del maestro a los discípulos, esa saturación de las almas porosas de éstos por el alma efusiva de aquél. Es preciso, para conocer una filosofía, haberse "empapado en ella" o inventarla. Tertium non datur y no cabe embriagarse en un filósofo sin embriagarse con su autor (Ortega, 2004: 19-20; v.t. Ortega, 1996a: 118).4

Compárense estas líneas con el siguiente texto de la Carta VII y podrá comprobarse hasta qué grado es Ortega platónico:

No hay, en efecto, ningún medio de reducirla a fórmulas, como se hace con las demás ciencias, sino que cuando se han frecuentado durante largo tiempo estos problemas y cuando se ha convivido con ellos, entonces brota repentinamente la verdad en el alma, como de la chispa brota luz [...] yo no creo que el razonar sobre esto sea, como se dice, un bien para los hombres, excepción hecha de una selección, a la que le bastan unas indicaciones para descubrir por sí misma la verdad (1999: 581).

La filosofía se aviene más al lenguaje hablado que al escrito. Hay para ello razones de método, como sus caracteres intuitivo y dialógico. Pero en el caso de Ortega a éstos se sumaba su circunstancia española, pues, como ha dicho, José Gaos, tanto la filosofía española como el pensamiento hispanoamericano, tienen preferencia por la palabra oral frente a la escrita (cfr. 1990: 58-87). «Ortega necesitaba cada día, perentoriamente cuando menos, tres horas de tertulia divididas entre la mañana y la tarde [...] y quien le había oído conversar seguía escuchándole a través de la letra impresa» (Díez del Corral, 1983: 99-100). Pues, como dice Thomas Mermall, «leyendo a Ortega se tiene la sensación de que los ensayos han pasado -y en efecto muchísimos pasaron- de la conferencia, del discurso o de la charla al periódico y al libro» (Mermall, 1997: 51). Sería interesante comparar el tamaño de la obra hablada y la escrita en Ortega. Según Fernando Salmerón, innovó la oratoria política, acercándola a la académica; añadiendo sistematismo y densidad a la tópica oratoria tradicional. Y logrando con ello un gran éxito, desde muy joven. Así, señala como los periódicos de la época destacaron el éxito de su conferencia en el Ateneo de Madrid de 1909 sobre Los problemas nacionales y la juventud (cfr. 1993: 15). En aquella época aparece en la figura de Antón Tejero en Troteras y danzaderas de Ramón Pérez de Ayala, salvando a la patria con el arma del mitin.

\footnotetext{
4 Merecía la pena reproducir estos largos textos, aunque no sea éste un contexto en que se esté viendo con buenos ojos los textos en general. En él nos está diciendo Ortega lo que hay que hacer con todo filósofo, incluyéndolo a él: inventarlo. La razón vital y la razón histórica son inventivas, imaginativas. Hay que crear una idea que concuerde con todos los datos, y que al relacionarlos jerárquicamente tengan sentido. Pero este inventar no tiene nada de subjetivo, pues, como nos dice su etimología, significa 'hallar'.Por eso no hay contradicción entre la intuición fenomenológica y la invención de hipótesis de la ciencia entendida en sentido antiinductivista.
} 


\subsection{El principio de autoctonía de las ideas}

La conciencia de la importancia de la circunstancia es también la razón de la antipatía que siente nuestro filósofo hacia la escolástica. En realidad, el llamado escolasticismo es sólo un caso del escolasticismo general que se ha dado y se da en todo lugar y tiempo: «llamo escolasticismo a toda filosofía recibida -frente a la creada-, y llamo recibida a toda filosofía que pertenece a un círculo cultural distinto y distante, en el espacio social o en el tiempo histórico, de aquellos en que es aprendida y adaptada» (VII: 47). «Trajes de viejos sistemas arreglados para otros cuerpos» (III: 253), la escolástica revela un total desconocimiento del funcionamiento de las ideas, de que lo verdaderamente importante de ellas no es lo que se piensa, aquello de que se tiene conciencia, sino lo que se soto-piensa bajo ellas, lo que queda sobredicho: «se traslada sólo el tallo y la flor y, acaso, colgando de las ramas, el fruto de aquel año [...] Pero queda en la tierra de origen lo vivaz de las "ideas", que es su raíz» ¡Y a eso se le llama filosofia perenne! Toda escolástica es un despropósito porque «la vida es siempre intransferible» (VII: 47).

El hecho de que este principio, al que Ortega llamó principio de autoctonía de las ideas, aparezca ya en el período neokantiano - «me atrevería a sostener como una ley histórica la afirmación de que las formas de la cultura son intransferibles» (I: 107)- hace sospechar lo que hace mucho sospechó José Luis Abellán, aunque por otra razón: que Ortega nunca llegó a creerse el neokantismo. ${ }^{5}$ Mas tarde Ortega llegaría a pensar que el neokantismo -como todo «neo»- no encerraba propiamente una filosofía, sino un escolasticismo (cfr. 1980: 16). En realidad, un invento para no trabajar, un aprenderse de memoria las cosas, sin entender nada, un repertorio de términos muertos: «todo escolasticismo es la degradación de un saber en mera terminología» (VII: 48). Sin embargo, su posición íntegra con respecto al neokantismo fue, para ser justos, más bien ambigua, pues, a pesar de sus críticas, valoraba la importancia de la misión histórica que le había sido asignada, pues «agotada la filosofía por el materialismo y el positivismo, que más bien que dos filosofías son dos maneras de ignorancia filosófica, perdió en aquel tiempo la mente europea la tradición escolar de esta ciencia. Fue, pues, necesario para recobrarla volver a la escuela» (VI: 306). El neokantismo hizo lo que pudo; entonces no se podía hacer más. Hay tiempos en que la actitud más auténtica consiste paradójicamente en lo contrario, en la inautenticidad.

\footnotetext{
5 La metáfora, el «temple» de Ortega, como ha dicho Julián Marías (1973: 41) está presente desde sus primeros escritos. Como en su período neokantiano este estilo metafórico no tiene nada que ver con el espíritu del neokantismo, ha dicho José Luis Abellán que causa sorpresa «un idealismo tan desmañadamente defendido» (1966: 76; v.t. Salmerón, 1959: 296).
} 


\section{La filosofía como historia de la filosofía}

Grecia fue profundamente antihistórica. Aristóteles, cuando se embarca en un tema, repasa antes las posiciones de sus predecesores, pero no lo hace con espíritu histórico, sino tratándolos como contemporáneos suyos, para ver qué puede sacar de bueno de ellos. Los coleccionistas de opiniones son los iniciadores de toda disciplina, y los coleccionistas griegos de opiniones filosóficas -como Diógenes Laercio, quien las cuenta como si fueran chismes de portera- proporcionarán a los escépticos el material en que cimentar sus devastadoras conclusiones. En efecto, el escepticismo resaltará a bombo y platillo la disonancia de las opiniones, con lo que la ausencia de verdad estará servida. Igual que en el satisfechísimo siglo XVIII, a que habrá que esperar para encontrar una nueva aportación al tema, si bien las filosofías anteriores parecerán erróneas no por su discordancia entre sí, sino por su discordancia con las felices ideas dieciochescas. El siglo XIX traerá de la mano el «sentido histórico» ${ }^{6}, \mathrm{y}$, con él, la historia de la filosofía como una evolución ordenada de doctrinas, donde ya no se verán como errores, sino como aciertos parciales en el camino hacia una filosofía definitiva. En efecto, tanto en Hegel como en Comte, la historia de la filosofía desemboca finalmente en sus propias filosofías. De modo que ésta fue la primera consecuencia del sentido histórico: trazarle un final a la historia, esto es, anularla (cfr. VI: 394-395, 416-417). Tan paradójica e impropia situación sólo podía solucionarse añadiendo un nuevo eslabón a la cadena de las formas de contemplar la historia de la filosofia: contemplar siempre la última filosofía, la filosofía actual, como si fuera penúltima.

\subsection{La dialéctica de la historia de la filosofía}

En los papeles de en torno al año 1943 que nos han llegado con el título de «Origen y epílogo de la filosofía», podemos leer como, una vez acabada la lectura de la Historia de la filosofía de Julián Marías, Ortega va a aplicar a su estudio la razón vital. O, mejor dicho, no va a hacer nada, sino dejar libre a la razón, cuyo funcionar espontáneo es la razón vital. Con sus propias palabras: «al concluir la lectura de una historia de la filosofía, se manifiesta ante el lector, en panorámica presencia, todo el pasado filosófico. Y esta presencia dispara en el lector [...] una serie

\footnotetext{
6 «Acaso la conquista más delicada de la Edad Contemporánea [...] es el sentido histórico» (II: 516), la última gran conquista de la cultura occidental (cfr. VI: 298). Ahora bien, el sentido histórico, así como la Historia, son un producto del romanticismo, de los historiadores alemanes. Es por lo que es más que probable que acierte Félix Martínez Bonati cuando considera que la posmodernidad se remonta al romanticismo (cfr. 2000: 8-9). Ésta se apagó durante la segunda mitad del XIX, aunque perviviendo en algunos autores como Nietzsche, y resurgió con fuerza en la crisis de fin de siglo. Por algo escribe José Luis Abellán que Unamuno era en definitiva «un neo-romántico de la generación del 98, quizá toda ella, una generación de neo-románticos» (2006: 90).
} 
dialéctica de pensamientos» (IX: 349-351). Obsérvese que Ortega se refiere a un lector en general. La serie dialéctica que viene a continuación no es arbitraria ni subjetiva, sino que habrá de recorrerla todo el que se ponga a pensar en el pasado de la filosofía. Lo mismo que un experimento científico puede ser repetido en cualquier laboratorio, así esta serie se impone a cualquiera que medite sobre ella.

El primer pensamiento que espontáneamente nos viene a las mientes es que la historia de la filosofía es la historia de los errores (cfr. IX: 353-354); que, como escribía melancólicamente Hegel, «cuando volvemos la vista al pasado lo primero que vemos es ruinas». ¿Cómo no sacar esta conclusión, si la historia de la filosofía es un guirigay de opiniones, todas discordantes, acusándose recíprocamente de error? La filosofía presume y promete sensatez, y, luego, resulta que lo que ofrece es una escena de manicomio. Cuando los griegos crearon y luego recogieron suficiente sustancia filosófica como para poder reflexionar un poco sobre ella, la primera impresión que tuvieron fue la escéptica: el famoso tropo de Agripa de la «disonancia de las opiniones».

Sin embargo, la primera opinión que tenemos de las cosas suele ser superficial y casi siempre equivocada. Normalmente, la sustituimos por otra más adecuada y justa, porque en «toda cuestión, somos primero aprendices, y solo más tarde maduros conocedores» (XI: 28). El problema de los escépticos griegos es que se quedaron en esta primera impresión, que no siguieron adelante. A nosotros nos resulta familiar porque también es la nuestra; el escepticismo filosófico es la filosofía popular, consecuencia del imperialismo de la física y del terrorismo de los laboratorios que venimos padeciendo últimamente. La filosofía del hombre de la calle es hoy escéptica, y una de las razones que la apoyan es la disonancia de las opiniones. Sin embargo, este hecho tan sólo puede impresionar al espíritu burgués, cobarde y gregario por esencia. Al margen de este espíritu, la sensación que se debe tener es que la verdad no tiene nada que ver con la democracia (cfr. VI: 320). Una cosa es la democracia en política, de la que Ortega nunca dudó, y otra el pretender extenderla «morbosamente» a todos los campos de la cultura.

La democracia, como democracia, es decir, estricta y exclusivamente como norma del derecho político, parece una cosa óptima. Pero la democracia exasperada y fuera de sí, la democracia en religión o en arte, la democracia en el pensamiento y en el gesto, la democracia en el corazón y en la costumbre es el más peligroso morbo que puede padecer una sociedad (II: 135),

escribió en su artículo «Democracia morbosa» de 1917.

Por otra parte, y para ser justos del todo, lo cierto es que a la noción de que la historia de la filosofia sea la historia de los errores no llegamos basándonos sólo en el argumento de la disonancia, sino también en el hecho de que cada filosofía se ha ocupado de demoler a la precedente. «La historia de la filosofía, a la vez que expo- 
sición de los sistemas, resulta ser, sin proponérselo, la crítica de ellos [...] No es, pues, solo el hecho abstracto de la "disonancia" quien nos presenta el pasado como error sino el pasado mismo quien se va, por decirlo así, cotidianamente suicidando, desprestigiando y arruinando» (IX: 353-354). La historia de la filosofía se nos muestra como el campo de batalla a que se refería Kant, donde todos luchan contra todos, sin que ninguno consiga ni por asomo la más pírrica victoria. La primera impresión sobre la historia de la filosofía resulta, por tanto, bastante deprimente.

Sin embargo, las cosas no son tan sencillas; las cosas no son nunca sencillas. Habrá que reconocer que, por lo menos, algo bueno debe tener tanto homicidio, que algo se habrá ganado al percatarse de que alguna idea, alguna doctrina, algún camino filosófico son equivocados, pues gracias a ello podremos eludirlos en el futuro, lo cual no es flaco favor. «La historia de la filosofía se muestra ahora como la de un gato escaldado que va huyendo de los hogares donde se quemó [...] En un segundo aspecto, pues, el pasado nos aparece como el arsenal y el tesoro de los errores» (IX: 354). De los errores, hemos pasado al tesoro de los errores. Y este es el segundo pensamiento.

El pensamiento es un pájaro extraño que se alimenta de sus propios errores. Progresa merced al derroche de esfuerzo con que se dedica a recorrer hasta el fin vías muertas. Sólo cuando una idea se lleva hasta sus últimas consecuencias revela claramente su invalidez. Hay, pues, que embarcarse en ella decidido, con rumbo al naufragio. De esta manera se van eliminando las grandes equivocaciones y va quedando exenta la verdad. El hombre necesita agotar el error para acorralar el cuerpo arisco de la verdad (IV: 507).

Vayamos ahora al tercero. Porque, si seguimos meditando dialécticamente, nos daremos cuenta de que las filosofías que antecedían a la nuestra no eran falsas por ser erróneas, sino por ser verdades a medias. Es imposible que no tuvieran nada de razón, que no contuvieran una porción de verdad por pequeña que fuera; y también imposible de que la tuvieran toda, toda la razón. "Vemos los errores como verdades incompletas, parciales o, como solemos decir, "tienen razón en parte", por tanto, que son partes de la razón» (IX: 359). Nuestros antecesores, por diversas circunstancias, se pararon, no siguieron pensando. A nosotros, en aquellas circunstancias, aquellas filosofías nos habrían parecido, como a ellos, la verdad misma. Una persona que sólo conociera una filosofía, que no pudiera contrastarla con otras, esa filosofía le parecería la verdad entera y redonda. De igual forma, la filosofía de nuestra época nos parece verdadera porque no podemos contrastarla con la filosofía del futuro. Ahora bien, si toda filosofía que no sea la nuestra nos parece insuficiente, se debe al esfuerzo que otros realizaron y del que nosotros nos aprovechamos.

$\mathrm{Y}$ este razonamiento nos coloca en el umbral del cuarto pensamiento. En él entramos pensando, en efecto, que nos aprovechamos del esfuerzo y de los logros de nuestros predecesores; pero, una vez dentro, aprenderemos que la labor de aque- 
llos, al ser completada, no queda exactamente igual que la presentaron, sino integrada, asimilada, esto es, abolida y conservada a la vez.

De esta suerte, la serie de los filósofos aparece como un solo filósofo que hubiera vivido dos mil quinientos años y durante ellos hubiera «seguido pensando» [...] En vez de representarnos el pasado filosófico como una línea tendida horizontalmente en el tiempo, el nuevo aspecto nos obliga a figurarla en línea vertical porque ese pasado sigue actuando, gravitando en el presente que somos. Nuestra filosofía es tal cual es, porque se halla montada sobre los hombros de las anteriores -como el número de la «torre humana» que hace la familia de acróbatas en el circo. $\mathrm{O}$, si se prefiere otra figura, véase a la humanidad filosofando como un larguísimo camino que es forzoso recorrer siglo tras siglo, pero un camino que, conforme se va haciendo, se va enrollando sobre sí mismo y, cargado al dorso del caminante, de camino se transforma en equipaje (IX: 360$361)$.

«Como Goethe decía que "solo todos los hombres viven lo humano", cabe insinuar que la filosofía ha de hacerse con la propia cabeza, más la de todos los filósofos sidos» (VI: 294).

La historia de la filosofía progresa en dirección subterránea, esto es, en radicalización. Desde más abajo, se ve la insuficiente bajura de los de arriba; pero, claro, hay que estar debajo para poder verlo (cfr. VIII: 270, 284). Por ejemplo, una vez que hemos alcanzado en filosofía el concepto de orientación, es bien fácil advertir la insuficiencia del concepto de mero saber. En efecto, la orientación no es un mero saber, por más que el saber forme parte de la orientación. Ahora bien, para llegar a la orientación, hay que hacerse cuestión del saber por el saber, cosa que durante siglos ha parecido ser un mandamiento filosófico.

De aquí que, contra lo que vulgarmente se cree, no es tanta la disonancia de las opiniones en la historia de la filosofía. En ella hay más solidaridad que, por ejemplo, en la historia de la ciencia. «La astronomía ptolomeica ejerce escaso influjo, por no decir nulo, sobre la astronomía actual. Platón o Aristóteles, en cambio, son de hoy tanto como de ayer, al menos por lo que hace a la línea medular de su pensamiento» (VI: 295-296). En ninguna otra ciencia tiene su propia historia tanto valor como en la filosofía (cfr. VI: 292). Es más; Ortega llega a asegurar que «no solo resalta el fondo idéntico de todas las filosofias, sino que sus diferencias esenciales adquieren un sentido de necesarias modulaciones que aquél idéntico se ve obligado a producir precisamente para mantenerse fiel a sí mismo» (VI: 298).

Recapitulando, la razón dialéctica nos ha mostrado cuatro caras de la historia de la filosofía. Pero no todas las vistas se han ido produciendo desde igual distancia del objeto, sino que cada vez nos hemos ido acercando más; se ha tratado de una penetración, una profundización. Es el método de Jericó, pues la serie dialéctica es una serie en espiral. Estas cuatro perspectivas han sido las siguientes: 1) errores, 2) teso- 
ro de los errores, 3) verdades parciales y 4) integración de verdades parciales. La razón vital nos ha enseñado que «todo ensayo filosófico atiende, pues, dos instancias: lo que las cosas son y lo que se ha pensado sobre ellas. Esta colaboración de las meditaciones precedentes le sirve, cuando menos, para evitar todo error ya cometido, y da a la sucesión de los sistemas un carácter progresivo» (III: 145).

En Origen y epílogo de la filosofía, al llegar al cuarto miembro de la serie, Ortega no continúa por no parecerle el momento, pero indica que podría continuarse, dando unas, aunque breves, iluminadoras indicaciones, como por ejemplo la idea de que la filosofía toda es un mero miembro de una serie dialéctica más amplia, que englobaría todas las formas de pensamiento, como las que había antes de que ella surgiera (cfr. IX: 366).

Por otra parte, en el Prólogo a la Historia de la filosofía de Émile Bréhier, de 1942, que, como vemos, es más o menos de la misma época que el Origen y epílogo de la filosofia, Ortega nos proporciona sabrosas indicaciones con que completar las anteriores ideas sobre la historia de la filosofía, como la historia de la filosofía como regreso y como progreso.

Por lo pronto, hay modos y modos de dedicarse a la filosofía, unos auténticos y otros inauténticos. A quien se dedica a la filosofía para ganarse la vida o por mera curiosidad, le bastará con asimilar una filosofía ya hecha; mas quien de verdad la siente, no se conformará con ello, sino que la elaborará como si él fuera el único, el primer filósofo que ha habido en el mundo. «La historia de la filosofía es, pues, en su primer movimiento un regreso del filósofo al origen de su tradición» (VI: 407). Se trata de la historia de la filosofía como regreso.

Sin embargo, como ya vimos anteriormente, la filosofía también es progreso. La filosofía que el filósofo auténtico crea es ineludiblemente la de su tiempo, resultado a su vez de toda la tradición filosófica. La filosofía es un viaje de ida y vuelta. ${ }^{7}$ En filosofia, la ingratitud que revela no contar con el pasado es lo de menos, lo peor es la ceguera y el suicido que implica. La filosofía es a la vez regreso y progreso:

La filosofía toda es solo una inmensa tradición. El filósofo propende a hacerse la ilusión de lo contrario, porque, en efecto, la filosofía es el esencial intento de existir fuera de una tradición, esto es, de no vivir en forma de tradicionalidad [...] Pero la verdad es que la filosofía no es, a su vez, sino la tradición de la in-tradición. Hasta el punto de que la definición más verídica que de la filosofía puede darse -y harto más rica en contenido de lo que al pronto parece, pues parece no decir casi nada- sería esta de carácter cronológico: la filosofía es una ocupación a que el hombre occidental se sintió forzado desde el siglo VI a. de J.C. y que con extraña continuidad sigue ejercitando hasta la fecha actual (VI: 404-405).

\footnotetext{
7 «Entre leer un libro y estudiarlo va, por lo menos, esta clara diferencia: leer es recibir el pensamiento del autor; estudiar es reconstruirlo mediante la propia meditación. El estudioso de filosofía deberá acostumbrarse a no leer libros filosóficos. Si se deja llevar por la comodidad de la lectura está perdido: nunca será dueño de los problemas y métodos de su investigación» (VI: 294-295)
} 
La conclusión sería que «la historia de la filosofía es una disciplina interna de la filosofía y no un añadido a ella o curiosidad suplementaria» (VI: 402). Por eso, lo que hay que hacer al terminar la lectura de la historia de la filosofía es seguir hacia delante. El pasado filosófico es catapulta hacia el porvenir. Porque la historia de la filosofía es dialéctica, y «la dialéctica es la obligación de seguir pensando» (IX: 352).

\subsection{Bebe del pozo y deja tu puesto a otro}

Ortega pensaba de la dialéctica hegeliana que, además de ser una maquinaria entumecida y falta de vida, tenía aún un defecto más grave: se traicionaba a sí misma, se suicidaba al creerse definitiva. Pero, como era de prever, la dialéctica de Hegel, así como toda su filosofía, ha sucumbido en las fauces del tiempo.

Es utópica la pretensión de abarcar más parte de tiempo que la que nos ha tocado en el reparto, querer ir más alto de la altura que nos ha sido asignada. El filósofo está al fin a la 'altura de los tiempos' cuando se da cuenta de que de hecho lo está, cuando «no pensamos, no necesitamos pensar que nuestra filosofía sea la definitiva, sino que la sumergimos como cualquiera otra en el flujo histórico de lo corruptible. Esto significa que vemos toda filosofía como constitutivamente un error -la nuestra como las demás» (VI: 417).

Y, sin embargo, esto no implica una descalificación. Este error es un error al que se tiene derecho y obligación. Pues

una filosofía es la verdadera, no cuando es definitiva - cosa inimaginable, sino cuando lleva en sí, como vísceras, las pretéritas y descubre en estas el «progreso hacia ella misma». La filosofía es así historia de la filosofía y viceversa [...] En los sitibundos desiertos de Libia se suele oír un proverbio de caravana, que dice así: «Bebe del pozo y deja tu puesto a otro» (VI: 418). ${ }^{8}$

El siglo XIX era un siglo archisatisfecho, aún más que el felicísimo siglo XVIII. ¿Cómo no se iba a considerar así mismo la guinda de los siglos y el final de la historia?

Pero ahora caemos en la cuenta de que esos siglos tan satisfechos, tan logrados, están muertos por dentro. La auténtica plenitud vital no consiste en la satisfacción, en el logro, en la arribada. Ya decía Cervantes que «el camino es siempre mejor que la posada» [...] Nuestro tiempo, en efecto no se siente ya definitivo; al contrario, en su raíz misma encuentra oscuramente la intuición de que no hay tiempos definitivos, seguros, para siempre cristalizados, sino que, al revés, esa pretensión de que un tiempo de vida

\footnotetext{
8 Ortega nos revela que conoció este «formidable adagio» en el libro de A.M. Hassanein Bey, Lost Oase-Oasis perdidos-de 1923 (cfr. II: 677; VII: 293).
} 
-el llamado «cultura moderna»-fuese definitivo, nos parece una obcecación y estrechez inverosímiles del campo visual. Y, al sentir así, percibimos una deliciosa impresión de habernos evadido de un recinto angosto y hermético, de haber escapado y salir de nuevo bajo las estrellas al mundo auténtico, profundo, terrible, imprevisible e inagotable, donde todo, todo es posible: lo mejor y lo peor (IV: 159-160).

La primera noticia que nos llega de esta novedosa manera de contemplar toda filosofía, incluida la suya, se remonta a Investigaciones psicológicas (cfr. XII: 416) y a las Conferencias de Buenos Aires (cfr. 1996a: 102), ambos cursos de 1916. En ambos lugares añade Ortega que la contemplación de la propia filosofía como un eslabón más de la cadena filosófica es una «interpretación realmente democrática de la historia». Se ha exagerado la influencia de Spengler en Ortega, como ha hecho Ciriaco M. Arroyo, sobre todo con respecto al que él entiende segundo período o «vitalista», pues, cuando escribió su libro (cfr. 1968), Garagorri aún no había publicado las Investigaciones psicológicas. La posición de Ortega sobre Spengler fue a la vez admirativa y crítica. Valoraba de él su intención de hacer una historia exclusivamente histórica; pero criticó su idea de los ciclos, que no dejaba margen a la novedad. Ortega estaba convencido de que su filosofía no tenía nada que ver con Spengler y que las ideas de éste o eran de otros o estaban ya en el ambiente de la época. Ortega no pensaba, por ejemplo, que Occidente atravesara ninguna decadencia, idea que criticó muchas veces, incluso en La rebelión de las masas. Y, sin embargo, siempre se le atribuyó esta influencia, provocando las quejas de Ortega, que recordaba que si Spengler era conocido fue porque él se preocupó de que se tradujeran sus libros. (cfr. 1996a: 250; VI: 309-311; II: 613; III: 269; II: 374; II: 725; IV:196). Pero la diferencia fundamental está en que Spengler es nietzscheano, y, por tanto, relativista. En Las Atlántidas Ortega critica el relativismo de Spengler:

La obra de Spengler se estrangula a sí misma no advirtiendo que mostrar la relatividad de las culturas - de los hechos humanos históricos- es hacer faena absoluta. La historia, al reconocer la relatividad de las formas humanas, inicia una forma exenta de relatividad. Que esta forma aparezca dentro de una cultura determinada y sea una manera de ver el mundo surgida en el hombre occidental no impide su carácter absoluto. El descubrimiento de una verdad es siempre un suceso con fecha y localidad precisas. Pero la verdad descubierta es ubicua y ucrónica. La historia es razón histórica, por tanto, un esfuerzo y un instrumento para superar la variabilidad de la materia histórica, como la física no es naturaleza sino, por el contrario, ensayo de dominar la materia (III: 312 313).

«Reconocemos en la filosofía el rasgo fundamental que tiene de humana ocupación: ser utopía. Todo lo que el hombre hace es utópico y no tiene sentido exigir su realización plena» (VI: 418). No tiene sentido, pues, correr tras la filosofía definitiva, sino sólo atrapar la de nuestro tiempo, una filosofía «a la altura de los tiem- 
pos». Porque «más que todo en la vida, la filosofía es nivel» (VIII: 27), como dice Ortega a propósito de Hermann Cohen, reconociendo que este filósofo elevó el nivel de la filosofía. El mismo hecho de la existencia de la filosofía, su aparición, significó que la cultura alcanzó un nivel más alto, un nivel que no tenía el pensamiento prefilosófico.

Así, puede decir Ortega que «intentar la superación del idealismo [...] es aceptar el problema de nuestro tiempo, es aceptar nuestro destino» (VII: 393).

Para los antiguos, realidad, ser, significaba «cosa»; para los modernos, ser significaba «intimidad, subjetividad»; para nosotros ser significa «vivir»-por tanto-, intimidad consigo y con las cosas. Confirmamos que hemos llegado a un nivel espiritual más alto porque si miramos a nuestros pies, a nuestro punto de partida -el «vivir»- hallamos que en él están conservadas, integradas una con otra y superadas, la antigüedad y la modernidad. Estamos a un nivel más alto -estamos a nuestro nivel-, estamos a la altura de los tiempos (VII: 408).

\section{Conclusión}

La historia de la filosofía es una carrera de relevos; un pasarse los filósofos, unos a otros, la antorcha filosófica en dirección a un estadio al que no se llegará jamás. El que todo filósofo tenga derecho no sólo a la verdad, sino también a su descubrimiento, hace que ninguno lo agote por completo. Una cosa ha aprendido la filosofía desde el siglo XX, una vez superadas las utopías modernas: el carácter de limitación de toda experiencia vital. La verdad filosófica está limitada por las circunstancias, siendo las dos más importantes la raza y la época histórica. De cualquier forma, como Ortega, tenía una concepción histórica de la raza, al final la circunstancia espacial se reduce a la temporal. En la historia pasa como en la biografía de una persona, que a todo lo más que puede aspirarse es a no volver a caer en el error ya cometido -lo cual ya es mucho. Pero, la vida personal difícilmente puede aprovechar las biografías de las demás vidas: es biografía, no historia. En la historia de la filosofía todas las filosofías auténticas fueron verdad en su momento; ahora, en cambio, sólo en parte. «Diríase que la razón se hizo añicos antes de empezar el hombre a pensar y, por eso, tiene este que ir recogiendo los pedazos uno a uno y juntarlos» (IX: 359).

\section{Bibliografía}

Ortega y Gasset, José. Obras completas. 12 Vols. Madrid: Revista de Occidente/Alianza Editorial, 1983. 
Ortega y Gasset, José. «Medio siglo de filosofía». Revista de Occidente, 3, Madrid, 1980, 5-21.

Ortega y Gasset, José. Notas de trabajo. Epílogo... Madrid: Alianza, 1994.

Ortega y GASSET, José. Meditación de nuestro tiempo. Las conferencias de Buenos Aires, 1916 y 1928. Madrid: FCE, $1996 a$

Ortega y Gasset, José. En torno a Galileo. Edición de José Luis Abellán. Madrid: Espasa Calpe, $1996 b$

Ortega y Gasset, José. Obras completas. Vol. IV. Madrid: Taurus, 2004.

Abellán, José Luis. Ortega y Gasset en la filosofia española. Madrid: Tecnos, 1966.

Abellán, José Luis. María Zambrano: una pensadora de nuestro tiempo. Barcelona: Anthropos, 2006.

Cerezo Galán, Pedro. La voluntad de aventura. Barcelona: Ariel, 1984.

GaOs, José. Obras completas. Vol. VI. México: UNAM, 1990.

HuSSERL, Edmund. Investigaciones lógicas. Madrid: Revista de Occidente, 1929.

HUSSERL, Edmund. Ideas relativas a una fenomenología pura y una filosofía fenomenológica. México: FCE, 1949.

HusSERL, Edmund. Lógica formal y trascendental. México: UNAM, 1962.

HuSSERL, Edmund. Meditaciones cartesianas. Madrid: Tecnos, 1986.

Lasaga Medina, José. José Ortega y Gasset (1883-1955) Vida y filosofia. Madrid: Biblioteca Nueva, 2003.

MARÍAs, Julián. Ortega. Circunstancia y vocación 2. Madrid: Revista de Occidente, 1973.

Martínez Bonati, Félix. «El postmodernismo de Ortega y Gasset». Mester, 29, Madrid, 2000, 1-27.

Mermall, Thomas. «Un "postmoderno" inteligible: en torno al estilo filosófico de Ortega y Gasset». Revista de Occidente, 192, Madrid, 1997, 47-58.

Morón Arroyo, Ciriaco. El sistema de Ortega y Gasset. Madrid: Ediciones Alcalá, 1968.

Morón ARroyo, Ciriaco. «Unamuno y Ortega y Gasset: las variedades de la razón» En: Tu mano es mi destino. Congreso internacional Miguel de Unamuno. Flórez Miguel, Cirilo (Coord.). Salamanca: Universidad, 2000, 353-366.

Platón, Obras completas. Aguilar, Madrid, 1999.

SALMERón, Fernando. Las mocedades de Ortega y Gasset. México: UNAM, 1993.

Jesús Ruíz Fernández

IES Lázaro Cárdenas de Collado Villalba (Madrid) jjesusruizz@hotmail.com 